Article

\title{
From Landfills to the Dinner Table: Red Grape Pomace Waste as a Nutraceutical for Broiler Chickens
}

\author{
Cebisa Kumanda ${ }^{1,2}$, Victor Mlambo ${ }^{3, *(1)}$ and Caven Mguvane Mnisi ${ }^{1,2}$ \\ 1 Department of Animal Sciences, Faculty of Natural and Agricultural Science, North-West University, P Bag \\ x2046, Mmabatho 2735, South Africa; Cebisa.Kumanda@nwu.ac.za (C.K.); 23257539@nwu.ac.za (C.M.M.) \\ 2 Food Security and Safety Niche area, Faculty of Natural and Agricultural Science, North-West University, \\ P Bag x2046, Mmabatho 2735, South Africa \\ 3 School of Agricultural Sciences, Faculty of Agriculture and Natural Sciences, University of Mpumalanga, \\ P Bag x11283, Mbombela 1200, South Africa \\ * Correspondence: victormlambo@yahoo.co.uk or Victor.Mlambo@ump.ac.za; Tel.: +27-13-002-0249
}

Received: 10 February 2019; Accepted: 5 March 2019; Published: 1 April 2019

\begin{abstract}
The disposal of red grape pomace (GP) in landfills and by incineration has negative impacts on the environment. It is, therefore, imperative that alternative and sustainable ways of managing this waste product are identified. Using GP as a source of nutrients and beneficial bioactive compounds in avian diets is a potential waste-reduction and valorization strategy that promotes sustainable agriculture. However, there is limited information on the valorization of GP for this purpose. This study, therefore, investigated the effect of dietary inclusion of GP on growth performance, blood parameters, carcass characteristics, and breast meat quality traits of broilers. Four hundred, two-week old Cobb 500 broilers $(279.2 \pm 18.87 \mathrm{~g})$ were allocated to 40 pens. Five isonitrogenous and isoenergetic diets were formulated by including GP in commercial broiler diets at 0 (GP0), 2.5 (GP25), 4.5 (GP45); $5.5 \%$ (GP55); and 7.5\% (GP75). Feed intake, weight gain, feed utilization efficiency, hematology, serum biochemistry, carcass characteristics, and breast meat quality traits were measured. Chickens on GP75 had the least feed intake $(p<0.05)$ but there were no dietary effects on weight gain. Birds on GP0 had the highest $(p<0.05)$ feed conversion ratio $(1.79)$ while those fed GP75 had the lowest $(p<0.05)$ ratio (1.45). Breast meat from broilers offered GP75 had the highest $(p<0.05)$ redness value $(0.75)$ while the GP0 diet promoted the least $(p<0.05)$ redness value $(0.49)$. Broilers fed GP55 and GP75 diets had higher $(p<0.05)$ feed conversion efficiency compared to GP0 birds. Inclusion of GP in broiler diets has the potential to reduce feed costs, thus making this valorization strategy a sustainable alternative to current pomace disposal methods. Adoption of this waste-reduction and valorization strategy promotes sustainable agriculture by contributing to food security and environmental stewardship.
\end{abstract}

Keywords: broiler diets; blood parameters; red grape waste; growth performance; meat quality; disposal methods

\section{Introduction}

Conservative estimates suggest that a third of all food produced ends up in landfills or incinerators, which exacerbates an already over-extended waste disposal system [1]. Reduction and valorization of food chain supply waste is critical in order to reduce the number of people that are food insecure. Indeed, most countries have committed to halving food waste by 2030 in recognition of threats to achieving sustainable development goals of food security, environmental protection, and energy efficiency caused by first-generation waste disposal methods [2]. Some of the sustainable valorization strategies for agro-waste include use as animal feed, animal bedding, organic fertilizers, heat, and cooking fuel [2]. When used as animal feed or organic fertilizers, agro-wastes make a direct contribution 
to food and nutrition security by supporting the production of animal and crop products for human consumption. Vineyards and wineries are some of the major generators of agro-waste because grapes are the world's largest fruit crop. Valorization of agro-wastes such as grape pomace through alternative uses requires access to their chemical and nutritional composition data. This is especially important if the waste is to be used as an alternative source of nutrients and bioactive compounds in animal feeds.

The red grape vinification process produces large quantities (about $25-30 \%$ of the original weight of fruit used) of grape pomace (skin, pulp, and seeds) [3]. In some vineyards, the pomace is incorporated into the soil after 6-9 months of composting with the aid of a variety of inoculants in order to recycle nutrients [4]. Unfortunately, this is a costly and, therefore, less-preferred option. Incorporating fresh red grape pomace (GP) into the soil without composting may negatively affect soil fertility due to its low $\mathrm{pH}$, presence of phenolic compounds that have antimicrobial properties, as well as the ability to bind and reduce the availability of some plant nutrients [5]. Most wineries in developing countries elect to dispose this 'waste product' in landfills or through burning resulting in environmental pollution. However, grape producers and wine makers have recently come under increased pressure from environmental organizations, governments, and consumers to reduce the negative environmental impact of GP disposal by adopting sustainable waste management practices.

Revalorization of GP as a nutraceutical in chicken diets would provide an environmentally sustainable, lower-cost alternative to current disposal methods, with the potential to improve food and nutrition security while providing health benefits to consumers of poultry products. Indeed, the GP is rich in phenolics, which have antimicrobial and antioxidants properties [6], as well as pigments that may positively alter the color and shelf stability of broiler meat. The antimicrobial properties of GP bioactive compounds may allow this waste product to be used in place of antibiotics in broiler diets given the concerns regarding antibiotic residues in poultry products as well as possible development of resistance to antibiotics by pathogenic microbes. Polyphenols in GP have the potential to prevent oxidative damage of biological molecules resulting in improved growth performance and meat quality $[7,8]$. In addition, GP polyphenols have been reported to boost the levels of glutathione and catalase, molecules that enhance immune function [9]. With respect to meat stability, dietary GP has been reported to delay meat lipid oxidation, thus enhancing the shelf-life of chicken meat [10]. Consequently, using GP as a feed ingredient has the potential to enhance broiler performance and meat quality, while addressing the environmental challenges posed by the currently preferred first-generation disposal methods. While there is some scientific concordance regarding the positive effects of using GP in avian diets, there is less agreement on the optimal rates of inclusion of this by-product in broiler diets. The amount of GP that can be incorporated in broiler diets is limited by antinutritional components such as fiber and condensed tannins. The fiber in GP may negatively affect digestion and absorption of nutrients while condensed tannins can bind and reduce availability of nutrients such as proteins and carbohydrates [11]. Phenolic compounds of lower molecular weight may also get absorbed through the digestive tract and cause toxicity [12]. It is, therefore, imperative that the maximum tolerable levels of GP be determined for broilers by monitoring physiological and product quality changes in response to dietary GP. This study represents the first time that the nutraceutical value of red grape waste has been evaluated in broiler chickens from rearing to product harvesting with simultaneous monitoring for potential antinutritional as well as nutritional effects of the pomace. The study thus addresses an existing gap by providing a holistic approach to the evaluation of red grape pomace waste as a feed ingredient in broiler chickens. This study, therefore, investigated the effect of graded levels of grape pomace on growth performance, blood parameters, carcass characteristics, and breast meat quality parameters of Cobb 500 broiler chickens. We hypothesize that including GP in Cobb 500 broiler diets will improve physiological, carcass, and breast meat quality traits. 


\section{Material and Methods}

\subsection{Study Sites}

Fresh red grape (Vitis vinifera L. var. Shiraz) pomace (GP) was supplied by Blaauwklippen Wine Estate $\left(33.969^{\circ} \mathrm{S} ; 18.844^{\circ} \mathrm{E}\right)$ (Stellenbosch, South Africa) that experiences cold and wet winters, dry and hot summers, an average daily temperature of $16.4^{\circ} \mathrm{C}$, and receives average annual rainfall of $802 \mathrm{~mm}$. Soil types range from dark alluvial to clay. Broiler feeding trial was conducted during the winter season of 2018 when temperatures ranged from $-3{ }^{\circ} \mathrm{C}$ to $25^{\circ} \mathrm{C}$ at Molelwane Research Farm $\left(25^{\circ} 40.459^{\prime} \mathrm{S}\right.$, $26^{\circ} 10.563^{\prime} \mathrm{E}$ ) of the North-West University, South Africa. An overview of all the experimental steps undertaken in this study is presented in Figure 1.

\subsection{Diet Formulation}

Experimental diets were formulated to meet the nutritional requirements for grower and finisher broilers as recommended by National Research Council [13]. Five isonitrogenous and isoenergetic experimental diets were formulated by including GP in commercial broiler grower and finisher diets at $0 \%$ (GP0), 2.5\% (GP25), 4.5\% (GP45); 5.5\% (GP55); and 7.5\% (GP75) as shown in Table 1.

Table 1. Ingredient composition ( $\mathrm{g} / \mathrm{kg}$, as fed basis) of grape pomace-containing diets.

\begin{tabular}{|c|c|c|c|c|c|c|c|c|c|c|}
\hline \multirow{3}{*}{ Ingredients } & \multicolumn{10}{|c|}{${ }^{1}$ Dietary Treatments } \\
\hline & \multicolumn{5}{|c|}{ Grower } & \multicolumn{5}{|c|}{ Finisher } \\
\hline & GP0 & GP25 & GP45 & GP55 & GP75 & GP0 & GP25 & GP45 & GP55 & GP75 \\
\hline Grape pomace & 0 & 25 & 45 & 55 & 75 & 0 & 25 & 45 & 55 & 75 \\
\hline Soy oilcake & 245 & 197 & 149 & 124 & 74 & 168 & 110 & 72 & 40 & 0 \\
\hline Full fat soya & 10 & 10 & 55 & 86 & 151 & 55 & 125 & 168 & 210 & 259 \\
\hline Lysine & 1.4 & 2.5 & 2.8 & 2.8 & 2.8 & 1.7 & 1.9 & 1.8 & 1.8 & 1.7 \\
\hline Methionine & 1.4 & 1.3 & 1.1 & 1.1 & 0.9 & 1.5 & 1.5 & 1.3 & 1.2 & 1.1 \\
\hline Threonine & 0 & 0.1 & 0.1 & 0.1 & 0 & 0.1 & 0.1 & 0 & 0 & 0 \\
\hline Yellow maize & 709 & 712 & 686 & 668 & 633 & 751 & 714 & 690 & 670 & 640 \\
\hline Feed lime & 14.0 & 14.3 & 14.0 & 14.3 & 13.4 & 12.5 & 12.3 & 12.1 & 11.9 & 11.7 \\
\hline Monocalcium phosphate & 7 & 7.4 & 7.6 & 7.6 & 7.7 & 2.2 & 2.3 & 2.3 & 2.3 & 2.3 \\
\hline $\mathrm{NaCl}$ (fine salt) & 3.3 & 3.3 & 3.2 & 3.2 & 3.3 & 2.8 & 2.9 & 2.5 & 2.9 & 3.0 \\
\hline Sodium bicarbonate & 1.6 & 1.6 & 1.6 & 1.6 & 1.6 & 1.9 & 1.9 & 1.7 & 1.6 & 1.6 \\
\hline Axtra Phytase & 0.1 & 0.1 & 0.1 & 0.1 & 0.1 & 0.1 & 0.1 & 0.1 & 0.1 & 0.1 \\
\hline Olaquindox & 0.4 & 0.4 & 0.4 & 0.4 & 0.4 & 0.2 & 0.2 & 0.2 & 0.2 & 0.2 \\
\hline Premix & 0.5 & 0.5 & 0.5 & 0.5 & 0.5 & 2.5 & 2.5 & 2.5 & 2.5 & 2.5 \\
\hline Gluten 60 & 5.0 & 23.2 & 32.3 & 34.0 & 35.0 & & & & & \\
\hline Choline chloride & 0.8 & 0.8 & 0.8 & 0.8 & 0.8 & & & & & \\
\hline Salinomycin & 0.5 & 0.5 & 0.5 & 0.5 & 0.5 & & & & & \\
\hline Zinc bacitracin & & & & & & 0.5 & 0.5 & 0.5 & 0.5 & 0.5 \\
\hline Soy crude oil & & & & & & & & & & 1.3 \\
\hline
\end{tabular}

${ }^{1}$ Dietary treatments: GP0 = commercial broiler diet without grape pomace, GP25 = commercial broiler diet containing 2.5\% grape pomace, GP45 = commercial broiler diet containing $4.5 \%$ grape pomace, GP55 = commercial broiler diet containing 5.5\% grape pomace and GP75 = commercial broiler diet containing $7.5 \%$ grape pomace.

\subsection{Chemical Analyses}

Experimental diets and GP were sampled, oven-dried at $60^{\circ} \mathrm{C}$ until constant weight, and then milled (1 mm sieve; Retsch SM 100 cutting mill, Germany) for chemical analyses (Table 2). The diets were analysed for dry matter, organic matter, crude protein, crude fiber, and crude fat according to Association of Official Analytical Chemists [14]. Metabolizable energy content was predicted using models from NIRs SpectraStar XL (Unity Scientific, Australia). Calcium, phosphorus, sodium, chloride, and potassium content was analyzed according to the Agri-Laboratory Association of Southern Africa [15]. 
Table 2. Chemical composition ( $\mathrm{g} / \mathrm{kg}$, unless otherwise stated) of grape pomace-containing diets.

\begin{tabular}{ccccccccccc}
\hline & \multicolumn{9}{c}{${ }^{1}$ Dietary Treatments } \\
\cline { 2 - 12 } Parameters & \multicolumn{3}{c}{ Grower } \\
\cline { 2 - 12 } & GP0 & GP25 & GP45 & GP55 & GP75 & GP0 & GP25 & GP45 & GP55 & GP75 \\
\hline Dry matter & 893.7 & 895.0 & 897.7 & 899.3 & 902.6 & 888.6 & 892.9 & 895.5 & 898.1 & 901.4 \\
Organic matter & 844.1 & 846.9 & 849.7 & 851.1 & 853.9 & 848.9 & 852.7 & 854.9 & 857.3 & 860.1 \\
2 ME (MJ/kg) & 119.0 & 118.9 & 119.0 & 119.0 & 119.0 & 122.0 & 121.9 & 121.9 & 122.0 & 121.9 \\
Crude protein & 170.0 & 170.0 & 170.1 & 170.0 & 170.0 & 160.0 & 160.0 & 160.0 & 160.0 & 160.0 \\
Crude fat & 33.5 & 34.3 & 42.2 & 47.7 & 58.9 & 42.7 & 54.2 & 61.2 & 68.1 & 77.5 \\
Crude fibre & 25.0 & 35.6 & 45.4 & 50.7 & 61.4 & 35.2 & 46.7 & 53.7 & 60.6 & 69.7 \\
Calcium & 8.21 & 8.19 & 8.20 & 8.19 & 8.19 & 6.59 & 6.60 & 6.62 & 6.61 & 6.62 \\
Phosphorus & 4.99 & 4.91 & 4.86 & 4.83 & 4.77 & 3.41 & 3.40 & 3.38 & 3.35 & 3.33 \\
Sodium & 1.80 & 1.80 & 1.80 & 1.80 & 1.80 & 1.60 & 1.60 & 1.60 & 1.60 & 1.60 \\
Chloride & 2.81 & 3.00 & 3.00 & 3.00 & 3.00 & 2.50 & 2.50 & 2.50 & 2.50 & 2.50 \\
Potassium & 7.52 & 6.95 & 6.91 & 6.99 & 7.18 & 6.55 & 6.75 & 6.87 & 6.98 & 7.15 \\
\hline
\end{tabular}

${ }^{1}$ Dietary treatments: GP0 = commercial broiler diet without grape pomace, GP25 = commercial broiler diet containing $2.5 \%$ grape pomace, GP45 = commercial broiler diet containing $4.5 \%$ grape pomace, GP55 = commercial broiler diet containing $5.5 \%$ grape pomace, and GP75 = commercial broiler diet containing $7.5 \%$ grape pomace. ${ }^{2} \mathrm{ME}$ $=$ metabolizable energy.

\subsection{Feeding Trial}

The rearing and slaughter of broilers was approved by the Institutional Ethics Committee at the North-West University (NWU-00239-18-A5). The 400 day-old Cobb 500 broiler chicks were purchased from OptiChicks (Gauteng, South Africa) and reared on a commercial starter mash diet (Nutri-feeds, South Africa) for 10 days. The birds were then randomly and evenly allocated to 40 floor pens $(3.5 \times 1.0 \times 1.85 \mathrm{~m})$ such that each pen (experimental unit) carried 10 birds. The pens were created by subdividing a poultry house constructed with $1.5 \mathrm{~m}$ brick walls from the ground with the rest of the space, up to the roof, covered by wire mesh. The pens had a concrete floor, which was covered by wood shavings to create a deep-litter system. Experimental diets were randomly allocated to the pens such that each diet was replicated eight times. The birds were then adapted to the dietary treatments from day 11 to day 13 and measurements commenced from day 14 to day 42 . The chickens had free access to clean fresh water.
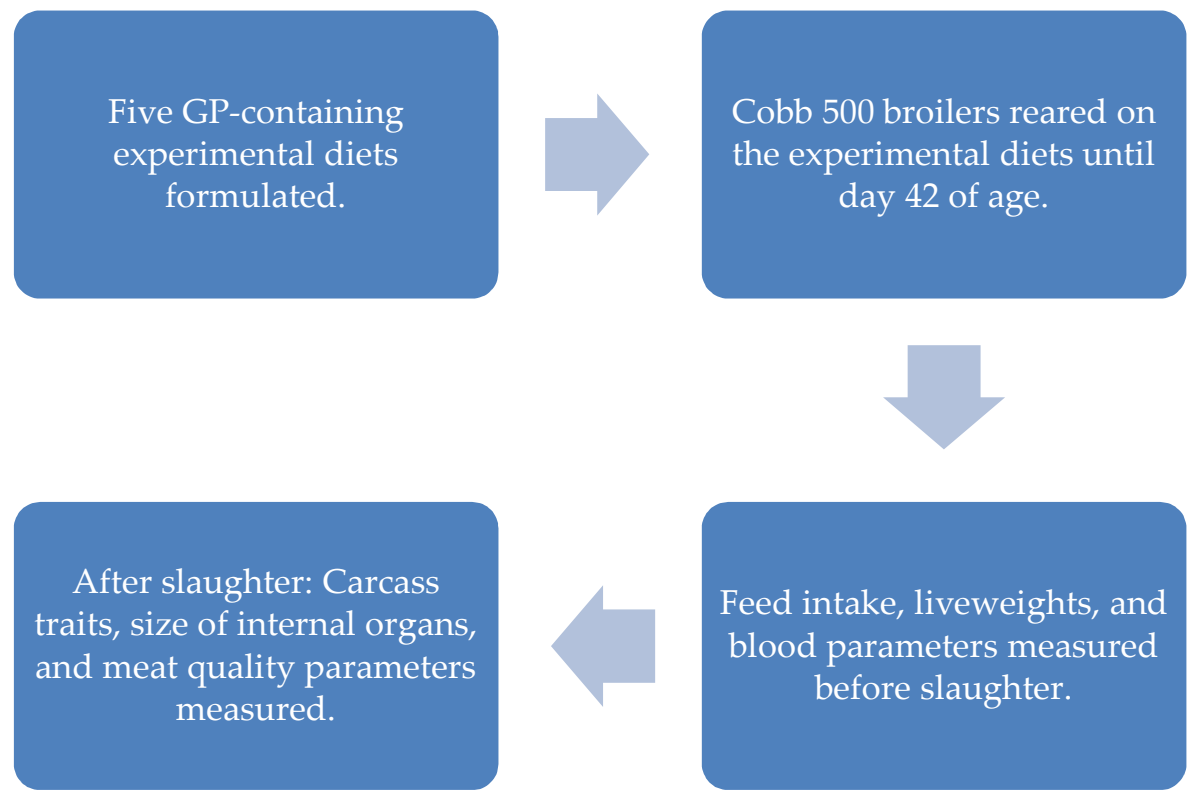

Figure 1. An overview of the experimental steps in the evaluation of red grape pomace-containing diets. 


\subsection{Feed Intake, Growth Performance and Blood Analyses}

Feed offered was weighed using a digital weighing scale (Explorer EX224, $0.01 \mathrm{~g}$ readability (2 decimal places) OHAUS Corp, Parsippany, NJ, USA) and refusals were collected and weighed each morning before the next feeding. Average weekly feed intake (AWFI) was calculated from week 2 to week 6 . All the birds were weighed at the beginning of the trial and weekly thereafter in order to determine average weekly weight gain (AWG). The AWG and AWFI were used to calculate the feed conversion ratio (FCR). At 40 days of age, blood was collected from the brachial vein from two broilers randomly selected from each pen. The blood was processed and stored according to the guidelines by Buetow et al. [16]. Blood was analyzed for hematology (erythrocyte count, hematocrit, hemoglobin, neutrophils, lymphocytes, monocytes, eosinophils, reticulocytes, white blood cells (WBC), and basophils) and serum biochemistry (glucose, calcium, creatinine, albumin, phosphorus, globulin, total bilirubin, alanine aminotransferase (ALT), alkaline phosphatase, gamma-glutamyl transferase (GGT), cholesterol, amylase, and lipase) using an automated IDEXX LaserCyte Hematology Analyzer and an automated IDEXX Catalyst One Chemistry Analyzer, respectively.

\subsection{Carcass Characteristics and Size of Internal Organs}

At day 42 , all broilers were starved for $13 \mathrm{~h}$, weighed (slaughter weight) using a digital weighing scale (Explorer EX224, 0.01 g readability ( 2 decimal places) OHAUS Corp, Parsippany, NJ, USA) and then transported to a local poultry abattoir for slaughter. The birds were electrically stunned and live-hung upside down onto a movable metal rack. The jugular vein was cut with a sharp knife and the birds were bled and defeathered. Carcasses were packaged by pen after which carcass traits and internal organs were measured. Hot carcass weight (HCW) was measured by weighing eviscerated carcasses with their necks but without giblets soon after slaughter, while cold carcass weight (CCW) was measured after chilling the carcasses at $4{ }^{\circ} \mathrm{C}$ for $24 \mathrm{~h}$. The ratio of HCW to slaughter weight expressed as a percentage was denoted as the dressing out percentage. Size of carcass parts (breasts, wings, drumsticks, and thighs) and internal organs (gizzards, proventriculi, and livers) was expressed as a proportion of HCW. Length of the small and large intestines was expressed in centimeters.

\subsection{Breast Meat Quality Traits}

Both temperature and $\mathrm{pH}$ were measured on the breast muscle $24 \mathrm{~h}$ after slaughter, using a spear-type electrode mounted on a Corning Model $4 \mathrm{pH}$-temperature meter (Corning Glass Works, Medfield, MA, USA). Calibration of the $\mathrm{pH}$ meter was carried out every 20 measurements with standard solutions of $\mathrm{pH} 4, \mathrm{pH} 7$, and $\mathrm{pH} 10$ (Ingold Messtechnik AG, Udorf, Switzerland). Meat color indices ( $L^{*}=$ lightness, $a^{*}=$ redness, and $b^{*}=$ yellowness) were determined $24 \mathrm{~h}$ post-mortem using a Minolta color-guide (BYK-Gardener $\mathrm{GmbH}$, Geretsried, Germany) on a $20 \mathrm{~mm}$ diameter measurement area and illuminant D65-day light, $10^{\circ}$ observation angle. The green standard was used to calibrate the color meter. Color measurements were taken from the breast muscle that had been allowed to bloom for $1 \mathrm{~h}$ on a polystyrene tray at $4{ }^{\circ} \mathrm{C}$. Hue angle was calculated as $\tan (\theta)=\frac{a *}{b *}$ and chroma was calculated as: $\sqrt{\left(a^{* 2}+b^{* 2}\right)}[17]$.

Water holding capacity (WHC) was measured in duplicate meat samples (8-16 g each) using freshly cut slices of the pectoralis major muscle. The WHC was determined as the amount of water expressed from meat samples held under $60 \mathrm{~kg}$ pressure using the filter-paper press method [18]. Expressed water was absorbed by a pre-weighed filter paper. Drip loss was determined according to Zhang et al. [19]. Cooking loss was measured as the loss in weight of breast meat samples upon oven-broiling at $140{ }^{\circ} \mathrm{C}$ for $20 \mathrm{~min}$ [20]. The values were expressed as a percentage of initial weight of raw breast meat samples. The same breast meat samples used to determine cooking loss were also used to measure shear force. The samples were sheared perpendicular to the fiber direction using a Meullenet-Owens Razor Shear Blade (A/MORS) mounted on a Texture Analyzer (TA XT plus, Stable Micro Systems, Surrey, UK). 


\subsection{Statistical Analysis}

Measured parameters were tested for normality using the NORMAL option in the Proc Univariate statement prior to analysis of variance. Data on AWFI, AWG, and weekly FCR were analyzed using repeated measures analysis [21]. The following statistical model was employed:

$$
Y_{i j k}=\mu+D_{i}+W_{j}+(D \times W)_{i j}+E_{i j k}
$$

where, $Y_{i j k}=$ dependent variable, $\mu=$ population mean, $D_{i}=$ effect of diets, $W_{j}=$ effect of week, $(D \times W)_{i j}=$ effect of interaction between diets and week, and $E_{i j k}=$ random error associated with observation $i j k$, assumed to be normally and independently distributed.

Blood parameters, carcass, and meat quality data were analyzed using the GLM procedure of the Statistical Analysis System [21]. The statistical model employed was:

$$
Y_{i j}=\mu+D_{i}+E_{i j}
$$

where, $Y_{i j}=$ dependent variable, $\mu=$ population mean, $D_{j}=$ effect of diets, and $E_{i j}=$ random error associated with observation $i j$, assumed to be normally and independently distributed. For all statistical tests, significance was declared at $P \leq 0.05$. Least squares means were compared using the probability of difference option in the LSMEANS statement of SAS.

\section{Results}

Repeated measures analysis revealed a significant diet $\times$ week interaction effect $(p<0.05)$ on AWFI but not AWG and FCR $(p>0.05)$. Table 3 shows that in week 3 , GP0 promoted higher AWFI than the GP-containing diets, which did not differ $(p>0.05)$. In weeks 4 and 5, broilers fed GP0 and GP25 diets had similar $(p>0.05)$ AWFI, while those on GP75 had the least $(p<0.05)$ AWFI. In week 6 , broilers fed diets GP0, GP25, and GP45 had higher $(p<0.05)$ AWFI than those fed diets GP55 and GP75.

\begin{tabular}{|c|c|c|c|c|c|c|c|}
\hline \multirow{2}{*}{ Week } & \multicolumn{6}{|c|}{${ }^{1}$ Dietary Treatments } & \multirow{2}{*}{${ }^{3}$ Significance } \\
\hline & GP0 & GP25 & GP45 & GP55 & GP75 & ${ }^{2}$ SEM & \\
\hline 3 & $454.8^{b}$ & $396.3^{a}$ & $381.3^{a}$ & $369.6^{a}$ & $370.3^{a}$ & 7.70 & $* * *$ \\
\hline 4 & $505.9^{d}$ & $484.4^{\mathrm{cd}}$ & $456.1^{\mathrm{bc}}$ & $421.7^{\mathrm{ab}}$ & $387.8^{\mathrm{a}}$ & 10.70 & $* * *$ \\
\hline 5 & $574.9^{\mathrm{c}}$ & $554.2 \mathrm{bc}$ & $581.1^{\mathrm{c}}$ & $504.8^{b}$ & $426.6^{\mathrm{a}}$ & 13.10 & $* * *$ \\
\hline 6 & $702.0^{\mathrm{b}}$ & $672.6^{\mathrm{b}}$ & $694.4^{b}$ & $564.7^{\mathrm{a}}$ & $521.8^{a}$ & 17.50 & $* * *$ \\
\hline
\end{tabular}

Table 3. Average weekly feed intake (g/bird) in broiler chickens fed diets containing grape pomace.

${ }^{1}$ Dietary treatments: GP0 $=$ commercial broiler diet without grape pomace, GP25 = commercial broiler diet containing $2.5 \%$ grape pomace, GP45 = commercial broiler diet containing $4.5 \%$ grape pomace, GP55 = commercial broiler diet containing 5.5\% grape pomace, and GP75 = commercial broiler diet containing $7.5 \%$ grape pomace. ${ }^{2}$ SEM: Standard error of the mean. ${ }^{3}$ Significance: ${ }^{* * *}=P<0.001$. ${ }^{\mathrm{a}, \mathrm{b}, \mathrm{c}, \mathrm{d}}$ In a row, dietary treatment means with common superscripts do not differ $(P>0.05)$.

Table 4 shows that diets had no effect on the overall WG of broiler chickens but influenced the overall FCR. Broilers fed diet GP75 had lower $(p<0.05)$ overall FCR $(1.45)$ than those fed diet GP $(1.79)$. 
Table 4. The effect of red grape pomace-containing diets on overall weight gain ( $\mathrm{g} / \mathrm{bird}$ ) and overall feed conversion ratio (FCR).

\begin{tabular}{|c|c|c|c|c|c|c|c|}
\hline \multirow{2}{*}{ Parameters } & \multicolumn{5}{|c|}{${ }^{1}$ Dietary Treatments } & \multirow{2}{*}{${ }^{3}$ SEM } & \multirow{2}{*}{${ }^{4}$ Significance } \\
\hline & GP0 & GP25 & GP45 & GP55 & GP75 & & \\
\hline${ }^{2}$ Overall WG & 1253.2 & 1205.9 & 1204.8 & 1172.1 & 1176.3 & 40.30 & NS \\
\hline${ }^{3}$ Overall FCR & $1.79^{\mathrm{a}}$ & $1.75^{\mathrm{ab}}$ & $1.75^{\mathrm{ab}}$ & $1.58^{b c}$ & $1.45^{\mathrm{c}}$ & 0.105 & $* * *$ \\
\hline
\end{tabular}

${ }^{1}$ Dietary treatments: GP0 = commercial broiler diet without grape pomace, GP25 = commercial broiler diet containing $2.5 \%$ grape pomace, GP45 = commercial broiler diet containing $4.5 \%$ grape pomace, GP55 = commercial broiler diet containing 5.5\% grape pomace, and GP75 = commercial broiler diet containing $7.5 \%$ grape pomace. ${ }^{2}$ Overall $\mathrm{WG}=$ overall weight gain. ${ }^{3} \mathrm{SEM}=$ Standard error of the mean. ${ }^{4}$ Significance: NS $=$ not significant; ${ }^{* * *}=p$ $<0.001$. ${ }^{a, b, c}$ In a row, dietary treatment means with common superscripts do not differ $(p>0.05)$.

There were no dietary effects $(p>0.05)$ on hematology, serum biochemistry, internal organ sizes, and carcass characteristics of broiler chickens (Table 5; Table 6).

Table 5. Hematological and serum biochemical parameters of broiler chickens fed red grape pomace-containing diets.

\begin{tabular}{|c|c|c|c|c|c|c|}
\hline & \multicolumn{5}{|c|}{${ }^{1}$ Dietary Treatments } & \multirow{2}{*}{${ }^{2} \mathrm{SEM}$} \\
\hline & GP0 & GP25 & GP45 & GP55 & GP75 & \\
\hline \multicolumn{7}{|l|}{ Haematology } \\
\hline Erythrocytes $\left(\times 10^{12} / \mathrm{L}\right)$ & 1.58 & 1.28 & 1.47 & 1.41 & 1.29 & 0.30 \\
\hline Haematocrit $(\%)$ & 11.30 & 12.55 & 11.61 & 11.69 & 11.78 & 0.82 \\
\hline Haemoglobin (g/dL) & 9.41 & 9.20 & 9.33 & 9.56 & 8.93 & 0.22 \\
\hline Neutrophils $\left(\times 10^{9} / \mathrm{L}\right)$ & 7.53 & 8.42 & 6.82 & 7.75 & 13.17 & 2.26 \\
\hline Lymphocytes $\left(\times 10^{9} / \mathrm{L}\right)$ & 22.43 & 11.78 & 11.55 & 19.43 & 16.42 & 5.87 \\
\hline Monocytes $\left(\times 10^{9} / \mathrm{L}\right)$ & 21.97 & 10.58 & 9.36 & 20.62 & 12.05 & 7.03 \\
\hline Eosinophils $\left(\times 10^{9} / \mathrm{L}\right)$ & 1.18 & 1.06 & 1.05 & 1.00 & 1.36 & 0.18 \\
\hline Reticulocytes $\left(\times 10^{9} / \mathrm{L}\right)$ & 314.5 & 335.1 & 293.8 & 211.2 & 166.1 & 87.9 \\
\hline White blood cells $\left(\times 10^{9} / \mathrm{L}\right)$ & 52.80 & 30.79 & 28.93 & 48.97 & 43.12 & 15.27 \\
\hline Basophils $\left(\times 10^{9} / \mathrm{L}\right)$ & 0.16 & 0.17 & 0.15 & 0.17 & 0.13 & 0.03 \\
\hline \multicolumn{7}{|l|}{ Serum biochemistry } \\
\hline Glucose (mg/dL) & 17.31 & 17.07 & 17.25 & 19.59 & 17.72 & 1.593 \\
\hline Calcium (mmol/L) & 3.34 & 3.48 & 3.20 & 3.46 & 3.18 & 0.212 \\
\hline Creatinine $(\mu \mathrm{mol} / \mathrm{L})$ & 9.64 & 9.57 & 9.67 & 9.71 & 9.00 & 0.444 \\
\hline Albumin $(\mathrm{g} / \mathrm{L})$ & 0.64 & 0.69 & 0.68 & 0.64 & 0.66 & 0.026 \\
\hline Phosphorus (mmol/L) & 2.66 & 2.93 & 2.77 & 2.71 & 2.64 & 0.207 \\
\hline Globulin (g/L) & 30.13 & 29.44 & 28.42 & 31.25 & 27.83 & 2.578 \\
\hline Total bilirubin $(\mu \mathrm{mol} / \mathrm{L})$ & 9.69 & 8.94 & 7.75 & 10.25 & 10.25 & 1.567 \\
\hline Alanine aminotransferase (IU/L) & 30,69 & 27.69 & 19.75 & 30.88 & 35.36 & 6.906 \\
\hline Alkaline phosphatase (IU/L) & 754.6 & 805.9 & 731.4 & 695.0 & 727.2 & 90.92 \\
\hline Gamma-glutamyl transferase (IU/L) & 31.64 & 29.06 & 31.33 & 34.44 & 24.00 & 3.037 \\
\hline Cholesterol $(\mathrm{mg} / \mathrm{dL})$ & 5.12 & 5.28 & 4.62 & 4.90 & 4.76 & 0.460 \\
\hline Amylase (IU/L) & 433.6 & 321.3 & 356.5 & 356.5 & 321.3 & 43.39 \\
\hline Lipase (IU/L) & 135.3 & 142.4 & 142.8 & 161.8 & 144.3 & 14.50 \\
\hline
\end{tabular}

${ }^{1}$ Dietary treatments: GP0 = commercial broiler diet without grape pomace, GP25 = commercial broiler diet containing $2.5 \%$ grape pomace, GP45 = commercial broiler diet containing $4.5 \%$ grape pomace, GP55 = commercial broiler diet containing $5.5 \%$ grape pomace, and GP75 = commercial broiler diet containing $7.5 \%$ grape pomace. ${ }^{2} \mathrm{SEM}$ : Standard error of the mean. 
Table 6. The effect of grape pomace-containing diets on carcass traits and size of internal organs (\% hot carcass weight (HCW) unless otherwise stated) of broilers.

\begin{tabular}{ccccccc}
\hline & \multicolumn{7}{c}{${ }^{\mathbf{1}}$ Dietary Treatments } & \multirow{2}{*}{ 2 SEM } \\
\cline { 2 - 6 } & GP0 & GP25 & GP45 & GP55 & GP75 & \\
\hline Carcass traits & & & & & & \\
Dressing percentage & 69.64 & 70.98 & 72.43 & 71.31 & 70.94 & 2.052 \\
Hot carcass weight (g) & 1299.6 & 1218.9 & 1256.5 & 1184.6 & 1155.6 & 43.19 \\
Cold carcass weight (g) & 1270.7 & 1229.2 & 1237.1 & 1161.9 & 1153.1 & 38.51 \\
Breast & 21.39 & 21.92 & 27.60 & 23.09 & 17.08 & 3.114 \\
Wing & 5.84 & 6.22 & 5.87 & 5.99 & 6.25 & 0.395 \\
Drumstick & 6.48 & 6.97 & 6.85 & 6.80 & 6.65 & 0.425 \\
Thigh & 8.01 & 8.61 & 8.11 & 7.94 & 6.68 & 0.529 \\
Internal organs & & & & & & \\
Gizzards & 3.03 & 3.17 & 3.28 & 3.13 & 3.34 & 0.101 \\
Proventriculi & 0.49 & 0.57 & 0.55 & 0.54 & 0.56 & 0.032 \\
Livers & 3.23 & 3.12 & 2.97 & 3.60 & 3.12 & 0.255 \\
Small intestines (cm) & 150.4 & 153.0 & 152.8 & 148.6 & 148.4 & 3.760 \\
Large intestines (cm) & 9.78 & 8.45 & 9.90 & 9.39 & 9.69 & 0.801 \\
\hline
\end{tabular}

${ }^{1}$ Dietary treatments: GP0 = commercial broiler diet without grape pomace, GP25 = commercial broiler diet containing $2.5 \%$ grape pomace, GP45 = commercial broiler diet containing $4.5 \%$ grape pomace, GP55 = commercial broiler diet containing $5.5 \%$ grape pomace, and GP75 = commercial broiler diet containing $7.5 \%$ grape pomace. ${ }^{2}$ SEM: Standard error of the mean.

Table 7 shows that diets influenced meat redness $\left(\mathrm{a}^{*}\right)$ and hue values. Breast meat from broiler chickens fed GP75 had the highest redness value (0.75), followed by diets GP25, GP45, and GP55 $(p>0.05)$, while the control diet (GP0) had the least redness value (0.49). Broilers fed the control diet had the highest hue value $(p<0.05)$ followed by those on diets GP25, GP45, and GP55, whereas those on GP75 had the least hue value (1.52). There were no dietary effects $(p>0.05)$ observed for the $\mathrm{pH}$, temperature, or chroma of breast meat.

Table 7. The effect of red grape pomace-containing diets on breast meat quality traits of broiler chickens.

\begin{tabular}{|c|c|c|c|c|c|c|c|}
\hline \multirow{2}{*}{$\begin{array}{c}\text { Meat Quality } \\
\text { Traits }\end{array}$} & \multicolumn{5}{|c|}{${ }^{1}$ Dietary Treatments } & \multirow{2}{*}{${ }^{2} \mathrm{SEM}$} & \multirow{2}{*}{${ }^{3}$ Significance } \\
\hline & GP0 & GP25 & GP45 & GP55 & GP75 & & \\
\hline Meat pH & 6.37 & 6.31 & 6.31 & 6.41 & 6.36 & 0.061 & NS \\
\hline $\begin{array}{c}\text { Temperature } \\
\left({ }^{\circ} \mathrm{C}\right)\end{array}$ & 25.90 & 26.56 & 26.47 & 26.30 & 26.38 & 0.480 & NS \\
\hline $\mathrm{L}^{*}$ & 55.92 & 57.31 & 56.34 & 55.53 & 56.32 & 0.786 & NS \\
\hline$a^{*}$ & $0.49^{a}$ & $0.62^{b}$ & $0.62^{b}$ & $0.66^{\mathrm{b}}$ & $0.75^{\mathrm{c}}$ & 0.020 & $* * *$ \\
\hline$b^{*}$ & 16.34 & 15.94 & 16.75 & 16.20 & 16.11 & 0.501 & NS \\
\hline Chroma & 16.35 & 15.95 & 16.77 & 16.21 & 16.13 & 0.500 & NS \\
\hline Hue angle & $1.54^{\mathrm{c}}$ & $1.53^{b}$ & $1.53^{b}$ & $1.53^{b}$ & $1.52^{\mathrm{a}}$ & 0.002 & $* * *$ \\
\hline
\end{tabular}

${ }^{1}$ Dietary treatments: GP0 = commercial broiler diet without grape pomace, GP25 = commercial broiler diet containing $2.5 \%$ grape pomace, GP45 = commercial broiler diet containing $4.5 \%$ grape pomace, GP55 = commercial broiler diet containing $5.5 \%$ grape pomace, and GP75 = commercial broiler diet containing $7.5 \%$ grape pomace. ${ }^{2} \mathrm{SEM}=$ Standard error of the mean. ${ }^{3}$ Significance: NS $=$ not significant; ${ }^{* *}=P<0.001 .{ }^{\mathrm{a}, \mathrm{b}, \mathrm{c}}$ In a row, dietary treatment means with common superscripts do not differ $(p>0.05)$.

Figure 2 shows that dietary treatments had no effect $(p>0.05)$ on water holding capacity (3.33-5.99\%), shear force (5.66-6.81 N) and drip loss (16.93-18.93\%), but affected $(p<0.05)$ cooking losses (18.16-26.13\%). There was a tendency for breast meat cooking losses to decline linearly as the level of GP in broiler diets increased (Figure 2). 


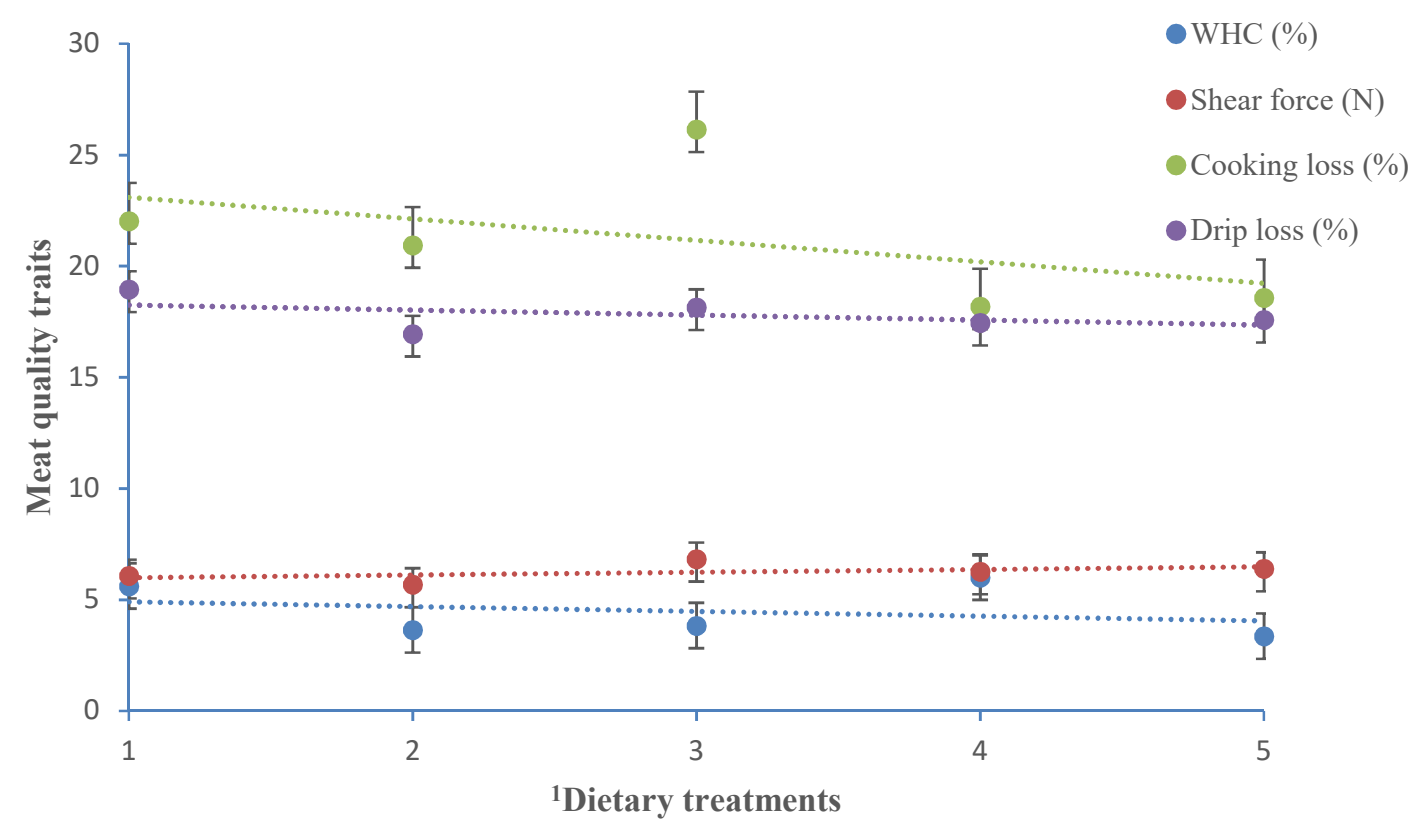

Figure 2. Water holding capacity (WHC), shear force, cooking loss, and drip loss of meat from broiler. Chickens reared on red grape pomace-containing diets. ${ }^{1}$ Dietary treatments: $1=$ commercial broiler diet without grape pomace, 2 = commercial broiler diet containing $2.5 \%$ grape pomace, $3=$ commercial broiler diet containing $4.5 \%$ grape pomace, $4=$ commercial broiler diet containing $5.5 \%$ grape pomace, and $5=$ commercial broiler diet containing $7.5 \%$ grape pomace.

\section{Discussion}

\subsection{Feed Intake, Utilization Efficiency, and Growth Performance}

Red grape pomace is a potential functional feed ingredient for poultry because it contains high levels of bioactive compounds, which have antioxidant and antimicrobial properties [12]. However, this by-product also contains anti-nutrients such as fiber and low molecular weight phenolic compounds. In light of this, it is imperative to identify the maximum tolerance level of red grape pomace in broiler chickens in order to optimize nutrient utilization, growth performance, and meat quality. Results from this study show that the highest inclusion level of red grape pomace $(7.5 \%)$ reduced overall feed intake, possibly due to higher levels of dietary fiber relative to other experimental the diets. Indeed, Singh et al. [22] reported that higher levels of dietary fiber reduce feed utilization in broilers. In addition, Lau and King [23] reported that broiler chicks fed diets containing grape pomace seed extract consumed less feed as the inclusion level of the extract increased. Owusu-Asiedu et al. [24] also concluded that the amount and type of fiber in a diet affects the gastrointestinal development and growth performance of broilers.

The reduction in feed intake in broilers receiving the highest level of GP did not result in lower overall weight gain. This suggests that the GP inclusion level was within the optimal range and, therefore, did not cause any significant changes in the physico-chemical properties of the diets. It could also be evidence of the GP's growth-boosting properties given that reduced feed intake did not result in reduced nutrient availability. The antimicrobial properties of bioactive compounds of phenolic origin in GP [25] may have suppressed the subclinical growth of pathogenic microbes in the gastrointestinal tract of broilers, thus boosting growth performance. This suggests that dietary inclusion of GP allows broilers to derive maximum utility from relatively lower amounts of feed consumed. These findings are similar to those of Aditya et al. [6] who demonstrated that dietary grape pomace did not significantly lower body weight gain in broilers despite some reduction in feed intake. Brenes et al. [12] also concluded that the addition of grape pomace concentrate up to $60 \mathrm{~g} / \mathrm{kg}$ in broiler chicken diets does not compromise the growth performance and size of organs. In the current study, 
diets containing GP promoted higher feed conversion efficiency compared to those offered the control diet. In contrast, Kara and Kocaoglu-Guclu [26] reported no effect of GP-containing diets ( $2 \%$ inclusion level) on feed conversion efficiency in moulted laying hens.

\subsection{Blood Parameters, Size of Internal Organs, and Meat Quality}

Hematological and serum biochemical parameters were not influenced by experimental diets and fell within the normal range for broilers. It was expected that GP-containing diets would negatively affect the hematological and biochemical parameters due to the presence of antinutritional compounds such as phenolics. The fact that these physiological parameters fell within the normal range for broiler chickens suggests that there was no negative effect of GP on the physiological status of the broiler chicken. Pascariu et al. [27] also reported that none of the blood erythrocyte parameters and antioxidant status of serum were influenced when chickens were fed grape pomace-containing diets. Similarly, Kara et al. [28] reported that including GP in hen diets at 40 and $60 \mathrm{~g} / \mathrm{kg}$ levels had no effect on serum triglycerides levels, while Ebrahimzadeh et al. [29] reported no variation in total protein, glucose, and cholesterol concentrations in the serum of chicks fed GP-containing diets. In contrast with current findings, Hajati et al. [30] concluded that grape seed extract supplementation $(150,300$, and $450 \mathrm{mg} / \mathrm{kg})$ reduces the concentration of serum glucose. Carcass characteristics and size of internal organs were not affected by experimental diets. Similar findings have been reported in References [6,9,12]. The size of internal organs was not affected by the GP-containing diets suggesting that GP inclusion did not induce anatomical adaptation responses in the birds. In contrast, Kara et al. [28] reported that including GP in diets of laying hens at $4 \%$ and $6 \%$ increased liver weight, an expected outcome given that the liver grows in size in response to higher levels of toxins such as the low molecular weight phenolics found in red grape pomace. In this study, there was no effect on the size of the liver suggesting that including GP in chicken diets at rates of up to $7.5 \%$ does not cause toxicity. There was no dietary effect on the $\mathrm{pH}$, temperature, and lightness of breast meat in agreement with the findings reported by Aditya et al. [6] for broilers. In this study, the redness of breast meat increased as the inclusion levels of GP increased, while the hue angle decreased with increasing inclusion levels of GP. These results were expected as the anthocyanin and free radicals in GP are known to improve the color and quality of meat [6].

\section{Conclusions, Limitations, and Future Research}

The hypothesis that including GP in Cobb 500 broiler diets will improve physiological, carcass, and meat quality traits was accepted for feed conversion efficiency and meat redness only. Dietary inclusion of red grape pomace up to $7.5 \%$ promoted similar levels of weight gain as the commercial control diet while enhancing meat redness. Higher inclusion levels of GP (5.5\% and 7.5\%) promoted higher feed conversion efficiency compared to the commercial control diet. Consequently, this valorization strategy for GP has the potential to improve food and nutrition security by boosting feed utilization efficiency while providing health benefits to consumers of poultry products. Incorporating red grape pomace waste in broiler diets is, therefore, a sustainable alternative to the first-generation pomace disposal methods that threaten environmental health. This approach is one of many actions that may help to reduce waste from wineries while improving food and nutrition security. The next step is to transfer this knowledge to wineries, poultry farmers, and government departments that are responsible for the formulation of policies, regulations and guidelines on the management of agricultural waste. The wider application of current research findings may be limited by the established fact that the chemical composition of GP varies widely depending on many factors such as growth environment, grape cultivar, and winemaking variables. This limitation can be overcome by chemical characterization of GP prior to its use in broiler diets. Further research is required to find ways to improve the feed intake of GP by broilers, especially when included in diets at high levels. This could be achieved by pre-treating the pomace with fibrolytic enzymes and polyethylene glycol to ameliorate the antinutritional effects of fiber and condensed tannins, respectively. 
Author Contributions: All three authors were equally involved in the conceptualization and execution of this investigation, data analysis, manuscript writing, and editing.

Funding: This research received no external funding.

Acknowledgments: This study did not receive any grant from funding agencies in the public, commercial, or not-for-profit sectors. We are grateful to North-West University for access to the research facilities used in this study.

Conflicts of Interest: The authors declare no conflict of interest.

\section{References}

1. WWF. Food Loss and Waste: Facts and Futures. WWF South Africa. 2017. Available online: http://awsassets. wwf.org.za/downloads/WWF_Food_Loss_and_Waste_WEB.pdf (accessed on 3 March 2019).

2. Ong, K.L.; Kaur, G.; Pensupa, N.; Uisan, K.; Lin, C.S.K. Trends in food waste valorization for the production of chemicals, materials and fuels: Case study South and Southeast Asia. Bioresour. Technol. 2018, 248, 100-112. [CrossRef]

3. Dwyer, K.; Hosseinian, F.; Rod, M. The market potential of grape waste alternatives. J. Food Res. 2014, 3, 91-106. [CrossRef]

4. Dillon, C. Waste Management in the South African Wine Industry. Master' Thesis, Cape Wine Academy, Cape Town, South Africa, 2011.

5. Muhlack, R.A.; Potumarthi, R.; Jeffery, D.W. Sustainable wineries through waste valorisation: A review of grape marc utilisation for value-added products. Waste Manag. 2018, 72, 99-118. [CrossRef]

6. Aditya, S.; Jip Ohh, S.; Ahammed, M.; Lohakare, J. Supplementation of grape pomace (Vitis vinifera) in broiler diets and its effect on growth performance, apparent total tract digestibility of nutrients, blood profile, and meat quality. J. Anim. Nutr. 2018, 4, 210-221. [CrossRef] [PubMed]

7. Alonso, A.M.; Guillén, D.A.; Barroso, C.G.; Puertas, B.; García, A. Determination of antioxidant activity of wine byproducts and its correlation with polyphenolic content. J. Agric. Food Chem. 2002, 50, 5832-5836. [CrossRef] [PubMed]

8. Yilmaz, Y.; Toledo, R.T. Health aspects of functional grape seed constituents. Trends Food Sci. Technol. 2004, 15, 422-433. [CrossRef]

9. Goni, I.; Brenes, A.; Centeno, C.; Viveros, A.; Saura-Calixto, F.; Rebolé, A.; Arija, I.; Estevez, R. Effect of dietary grape pomace and vitamin $\mathrm{E}$ on growth performance, nutrient digestibility, and susceptibility to meat lipid oxidation in chickens. J. Poult. Sci. 2007, 86, 508-516. [CrossRef] [PubMed]

10. Chamorro, S.; Viveros, A.; Rebole, A.; Rica, A.; Arija, B.D.; Brenes, A.A. Influence of dietary enzyme addition on polyphenol utilization and meat lipid oxidation of chicks fed grape pomace. Food Res. Int. 2015, 73, 197-203. [CrossRef]

11. Chamorro, S.; Viveros, A.; Alvárez, I.; Vega, E.; Brenes, A. Changes in polyphenol and polysaccharide content of grape seed extract and grape pomace after enzymatic treatment. Food Chem. 2012, 133, 308-314. [CrossRef]

12. Brenes, A.; Viveros, A.; Chamorro, S.; Arija, A. Use of polyphenol-rich grape by-products in monogastric nutrition. A review. Anim. Feed Sci. Technol. 2016, 211, 1-17. [CrossRef]

13. NRC. Nutrient Requirement of Poultry, Ninth Revised ed.; National Research Council: Washington, DC, USA, 1994. [CrossRef]

14. AOAC. Official Methods of Analysis of AOAC International, 16th ed.; Association of Analytical Chemists: Arlington, VA, USA, 2005.

15. Agri-LASA. Feed and Plant Analysis Methods; Agri-Laboratory Association of Southern Africa: Sasolburg, South Africa, 1998.

16. Buetow, B.S.; Treuting, P.M.; van Hoosier, G.L. The hamster. In The Clinical Chemistry of Laboratory Animals; Loeb, W.F., Quimby, F.W., Eds.; Taylor and Francis: Philadelphia, PA, USA, 1999; pp. 49-63.

17. Priolo, A.; Moorhead, D.; Agabriel, J. Effects of grass feeding systems on ruminant meat colour and flavour: A review. Anim. Res. 2002, 50, 185-200. [CrossRef]

18. Trout, G.R. Techniques for measuring water-binding capacity in muscle foods-A review of methodology. Meat Sci. 1988, 23, 235-252. [CrossRef] 
19. Zhang, L.; Yue, H.Y.; Zhang, H.J.; Xu, L.; Wu, S.G.; Yan, H.J.; Gong, Y.S.; Qi, G.H. Transport stress in broilers: I. Blood metabolism, glycolytic potential, and meat quality. Poult. Sci. 2009, 88, 2033-2041. [CrossRef] [PubMed]

20. Honikel, K.O. Reference methods for the assessment of physical characteristics of meat. Meat Sci. 1998, 49, 447-457. [CrossRef]

21. SAS. Users Guide; Statistical Analysis System Institute Inc.: Carry, NC, USA, 2010.

22. Singh, A.K.; Berrocoso, J.F.D.; Dersjant-Li, Y.; Awati, A.; Jha, R. Effect of a combination of xylanase, amylase and protease on growth performance of broilers fed low and high fiber diets. Anim. Feed Sci. Technol. 2017, 232, 16-20. [CrossRef]

23. Lau, D.W.; King, A.J. Pre- and post-mortem use of grape seed extract in dark poultry meat to inhibit development of thiobarbituric acid reactive substances. J. Agric. Food Chem. 2003, 51, 1602-1607. [CrossRef]

24. Owusu-Asiedu, A.; Patience, J.F.; Laarveld, B.; Van Kessel, A.G.; Simmins, P.H.; Zijlstra, R.T. Effects of guar gum and cellulose on digesta passage rate, ileal microbial populations, energy and protein digestibility, and performance of grower pigs. J. Anim. Sci. 2006, 84, 843-852. [CrossRef]

25. Peixoto, C.M.; Dias, M.I.; Alves, M.J.; Calhelha, R.C.; Barros, L.; Pinho, S.P.; Ferreira, I.C.F.R. Grape pomace as a source of phenolic compounds and diverse bioactive properties. Food Chem. 2018, 253, 132-138. [CrossRef]

26. Kara, K.; Kocaoglu-Guclu, B. The effects of different molting methods and supplementation of grape pomace to the diet of molted hens on postmolt performance, egg quality and peroxidation of egg lipids. J. Fac. Vet. Med. Univ. Erciyes 2012, 9, 183-196. [CrossRef]

27. Pascariu, S.M.I.; Pop, I.M.I.; Simeanu, D.I.; Pavel, G.I.; Solcan, C.I.E. Effects of wine by-products on growth performance, complete blood count and total antioxidant status in broilers. Braz. J. Poultry Sci. 2017, 9, 191-202. [CrossRef]

28. Kara, K.; Guclu, B.K.; Baytok, E.; Senturk, M. Effects of grape pomace supplementation to laying hen diet on performance, egg quality, egg lipid peroxidation and some biochemical parameters. J. Appl. Anim. Res. 2016, 44, 303-310. [CrossRef]

29. Ebrahimzadeh, S.K.; Navidshad, B.; Farhoomand, P.; Mirzaei Aghjehgheshlagh, F. Effects of grape pomace and vitamin $\mathrm{E}$ on performance, antioxidant status, immune response, gut morphology and histopathological responses in broiler chickens. S. Afr. J. Anim. Sci. 2018, 48, 324-336. [CrossRef]

30. Hajati, H.; Hassanabadi, A.; Golian, A.; Nassiri-Moghaddam, H.; Nassiri, M.R. The effect of grape seed extract and vitamin $\mathrm{C}$ feed supplementation on some blood parameters and HSP70 gene expression of broiler chickens suffering from chronic heat stress. Ital. J. Anim. Sci. 2015, 14, 3273-3282. [CrossRef] 